\title{
Influence of water activity on the properties of wheat flour
}

\author{
Andrii Marynin ${ }^{1}$, Vasyl Pasichny ${ }^{1}$, Svitlana Litvynchuk ${ }^{1}$, \\ Liubomyr Khomichak ${ }^{2}$, Inha Kuznietsova ${ }^{2}$, Svitlana Vysotska ${ }^{2}$
}

\author{
1 - National University of Food Technologies, Kyiv, Ukraine \\ 2 - Institute of Food Resources of NAAS, Kyiv, Ukraine
}

\section{Keywords:}

Grain

Wheat

Flour

Activity

Storage.

\section{Article history:}

Received

16.09.2020

Received in revised

form 01.03.2021

Accepted

30.06.2021

Corresponding

author:

Inha Kuznietsova

E-mail:

ingaV@ukr.net

DOI:

$10.24263 / 2304$

974X-2021-10-2-13

\section{Abstract}

Introduction. The purpose of the research is to determine the influence of water activity indicator on the quality of wheat flour and modified wheat flour.

Research methodology. Samples of wheat flour obtained from wheat grain of different starch polymer composition and component composition were using. The water activity index for wheat flour and modified according to ISO 18787:2017 was determined. In the bread recipe, $10 \%$ of flour was replaced by modified wheat flour. Determined the effect of improved formulation on the shelf life of loaves.

Research results. The highest value of enthalpy and water activity is for flour, which has a base ratio of amylose and amylopectin. Softening of the structure and weakening of the starch-protein matrix bonds reduces the enthalpy by $2.3 \mathrm{~J} / \mathrm{g}$ and the activity of water. The lowest value of enthalpy and water activity has flour, which contains only amylopectin in the starch granules. It should be noted, that the increased composition of micro- and macronutrients flour leads to a decrease in enthalpy of $3.7 \mathrm{~J} / \mathrm{g}$. Studies have shown that the physical modification of wheat flour leads to a change in water activity of the samples. In particular, is reduced from 0.619 to 0.591 . At the same time, the change in the structure of starch granules leads to an increase in water activity for flour samples: confectionery - from 0.477 to 0.585 , type "waxy" - from 0.542 to 0.570 , enriched with micro- and macronutrients - from 0.491 to 0.597 .

The use of ingredients with a reduced rate of aw shows an inhibitory ability to develop potato disease and micromycetes, which prolongs the storage of bread loaves for 1-2 days. The change in the component composition of the flour after its modification significantly affected its technological quality. The use of such a product in the production of food products helps to extend their shelf life, and, accordingly, for a long time to promote the preservation of organoleptic properties and to show stability to the action of microorganisms.

Samples of flour differ in the composition of carbohydrates ( $\mathrm{p}$ $<0,001)$, proteins $(\mathrm{p}<0,01)$, fats $(\mathrm{p}<0,05)$. Therefore, with temperature modification there are structural changes of the main components with the formation of simpler ones.

Conclusions. The water activity index for native wheat flour is in the range of $0.491-0.619$ and for modified wheat flour in the range of $0.570-0.597$. 


\section{— Food Technology —}

\section{Introduction}

The ingredients, such as wheat fiber, modified wheat flour, etc. are being introducing into the recipe of bakery and flour confectionery products to improve the quality and extend the shelf life (Venturi C et. al., 2016; Birch AN et. al., 2013). Modified flour is produce in a sufficiently full volume and can meet the needs of the food industry (Abbas K.A., et. al., 2010). At the same time, the influence of modified flour on the quality of bakery products remains unexplored; one of the criteria influencing the quality and storage of products is the indicator of water activity. In our opinion, the method of modification of starch in raw materials also has an effect on the change of water activity index (Rodel W., 2001).

In this regard, one of the key issues is the indicator that affects the structural properties of the product, shelf life and depends on the nature and amount of components soluble in the aqueous phase of the product (Scott WJ et. Al., 1957), as well as methods of processing raw materials, semi-finished products, etc. (Rodel W., 2001). Accordingly, the value of the indicator "water activity" (aw) is crucial, on which depends not only the forming indicator of the product but also the development of microorganisms (Rodel W., 2001). Since the gradient of values water activity of the product and relative humidity is the driving force of mass moisture exchange in various thermal and hydrothermal processes (Kataoka, Y. et. al., 2011), as well as storage (Chervenka L. et al., 2006), data on water activity of treated products are relevant to justify optimal processes (Kataoka, Y. et. al., 2011). The change in the indicator affects the possibility and intensity of development of microorganisms in bakery products (Sereno A. M., 2001).

Water activity (Červenka L. et al., 2006) was determined in such food products as: fruits (0.97), eggs (0.97), flour (0.80), jam (0.82-0.94) meat products. Foods such as milk powder, crackers and instant products have water activity $\left(\mathrm{a}_{\mathrm{w}}\right)$ values in the range of $0.35-0.5$, which usually show a property such as the fragility of the structure (Sereno A. M., 2001). Affects $\mathrm{a}_{\mathrm{w}}$ on the development of microorganisms in food (Červenka L. et al., 2006; Schmidt S.J., 2004) and defined the following limits for: bacteria $a_{w}=0.75-0.98$; yeast $a_{w}=0.62-0.90$; micromycetes $\mathrm{a}_{\mathrm{w}}=0.60-0.88$. Thus, the indicator of water activity affects the quality and storage of food. Thus, it is necessary to study the replacement of part of wheat flour in the recipe for the production of loaves of bread with modified flour, respectively, to study the change in the shelf life of the obtained loaves.

The so-called barrier technologies (Leistner L. and Gorris, L.G.M., 1995) have been developing for the production of a number of products aimed at ensuring the safety and quality of products with extended shelf life. Given that the water activity index was determined for a number of food products, it is important to determine this indicator for modified wheat flour, which is already produce by some starch companies (Chervenka L. et al., 2006), but little is studied.

The purpose of the research is to determine the influence of water activity indicator on the quality of wheat flour and modified wheat flour.

\section{Materials and methods}

\section{Materials}

The studies used wheat flour, which had a different structural composition of starch: 
- Sample 1 - flour with a ratio of starch granules of amylose: amylopectin as 30:70;

- Sample 2 - wheat flour from soft confectionery wheat has a low protein content (10.5-11.8\%), easily digestible, starchy flour and by weight 20-25\% lighter than baking wheat flour, which provides looseness flour confectionery. Flour obtained from such grain does not lose its whiteness when the yield is above 70\%, has a low water absorption capacity (54-55\%) (Rybalka OI and Axelrud DV, 2004);

- Sample 3 - wheat flour from soft wheat type "waxy" white color and has an extra high water absorption capacity (72\% and above) (Rybalka OI et. al., 2005);

- Sample 4 - wheat flour from soft wheat with an amylose: amylopectin ratio of 30:70 and enriched with micro- and macroelements. Flour obtained from such grain has a grayish-white color, black or dark brown bran, and has excellent food flavoring properties of cereals (Rybalka OI, 2008).

The samples used in the study had the following physicochemical parameters, which are shown in Table 1 (Kuznietsova I.V. et al., 2020).

Physic-chemical parameters of samples of wheat flour $(n=3, p \leq 0.05)$

Table 1

\begin{tabular}{|l|c|c|c|c|}
\hline \multirow{2}{*}{ Indicator } & \multicolumn{4}{c|}{ Wheat flour } \\
\cline { 2 - 5 } & Sample 1 & Sample 2 & Sample 3 & Sample 4 \\
\hline Content of hygroscopic water,\% & 10,54 & 13,78 & 9,52 & 10,19 \\
\hline Starch content, \% & 68,42 & 65,80 & 61,90 & 56,01 \\
\hline Ash content, $\%\left(550^{\circ} \mathrm{C}\right)$ & 1,78 & 1,86 & 1,93 & 1,94 \\
\hline Protein content, \% & 11,60 & 10,66 & 9,96 & 11,84 \\
\hline Fat content, \% & 1,9 & 1,4 & 2,0 & 2,1 \\
\hline Fiber content, \% & 6,5 & 6,2 & 6,8 & 7,8 \\
\hline
\end{tabular}

The control sample for modified samples of wheat flour is obtained in industrial conditions extruded wheat flour (Table 2) (Kuznietsova I.V. et al., 2020).

Physic-chemical parameters of the control sample $(n=3, p \leq 0.05)$

Table 2

\begin{tabular}{|l|c|}
\hline \multicolumn{1}{|c|}{ Indicator } & $\begin{array}{c}\text { Extruded flour } \\
\text { (control) }\end{array}$ \\
\hline Content of hygroscopic water, $\%$ & 9,13 \\
\hline Starch content, $\%$ & 64,91 \\
\hline Ash content, $\%\left(550^{\circ} \mathrm{C}\right)$ & 1,80 \\
\hline Protein content, $\%$ & 11,68 \\
\hline Fat content, $\%$ & 2,1 \\
\hline Fiber content, $\%$ & 6,7 \\
\hline Fiber content, $\%$ & \\
\hline
\end{tabular}




\section{Preparation of prototypes}

We have improved the method of obtaining physically modified flour. Which is the use of convective drying:

Modifications (Khomichak L.M. et al., 2019) of wheat flour samples with different structural composition of starch were performed. Modification of wheat flour samples was carried out by preparing them by brewing, followed by drying in a convective dryer at a temperature of $110-120^{\circ} \mathrm{C}$ for $30-45 \mathrm{~min}$ and at a temperature up to $60-65^{\circ} \mathrm{C}$ to obtain the product - flour modified with a dry matter content of 6-10\%, grinding and sifting (Khomichak L.M. and others, 2020).

The obtained samples of modified wheat flour with different starch composition were used to measure the water activity index.

According to the physical modification of the flour will be obtained appropriate samples of the modified flour:

With sample $1 \mathrm{M}$ - modified flour obtained from sample 1;

With sample $2 \mathrm{M}$ - modified flour obtained from sample 2;

With sample $3 \mathrm{M}$ - modified flour obtained from sample 3;

With sample $4 \mathrm{M}$ - modified flour obtained from sample 4.

\section{Description of methods and installation}

Determination of water activity of wheat flour samples and after their physical modification (Schmidt S.J., 2004).

The water activity index was determined according to the method described in ISO 18787:2017 for four samples of wheat flour and four samples of modified wheat flour, a sample of extruded wheat flour (control for samples of modified flour).

Measurement of thermodynamic parameters of all flour samples was carried out on the device Hygrolab-2 (Rotronic, Switzerland) at a temperature of $18-20{ }^{\circ} \mathrm{C}$ with a measurement accuracy of $1.5 \%, \mathrm{a}_{\mathrm{w}}+1.5 \%$ of the value.

Determination of the effect replacing part of wheat flour with modified in the recipe on the shelf life of loaves of bread

Determination of the effect of aw on the shelf life of the product using a modified sample 1 of flour was carried out by obtaining samples of loaves: on sourdough with wheat flour; on leaven with replacement of $10 \%$ of extruded flour; on leaven with replacement by $10 \%$ of the $1 \mathrm{M}$ sample. The obtained samples of loaves were stored for 12 days.

Determination of structural and mechanical properties, crumbliness and microbiological spoilage during storage of bread loaves.

Investigations of the structural and mechanical properties of breadcrumbs were performing on an automated penetrometer. The method consists in measuring the amount of immersion (penetration) of a body of a certain shape and size under the influence of a certain load for a certain time.

Determination of breadcrumbs is an indicator that characterizes the freshness of bread or the degree of its hardening. From the crumb cut two pieces in the shape of a parallelepiped of $5 \mathrm{~g}$ each and transfer to a conical flask with a volume of $250 \mathrm{~cm}^{3}$. Shake the flask for 5 
minutes. The crumb formed as a result of friction of two pieces is collected and weighed on scales with an accuracy of $0.01 \mathrm{~kg}$.

To determine the effect of yeasts on wine yeast and flour types on the microbiological stability of loaf samples were studied as follows. Products manufactured by intensive technology (Pico J., et. al. 2015; Torrieri E., et. al. 2014) were placed at a temperature of 35 $40{ }^{\circ} \mathrm{C}$ in provocative conditions to observe the appearance of signs of potato disease and the development of micromycetes.

\section{Results and discussion}

It was studied the change $a_{w}$ for wheat flour and after its modification, which will show the effect of physical modification on this indicator and, accordingly, on product quality and allow to predict the shelf life of food obtained with modified wheat flour in the recipe.

\section{Determination of $a_{w}$ for wheat flour samples}

Table 3 presents the indicators. For which the measurement of water activity was performed. It should be noted that the enthalpy values are different for flour samples, which indicates the effect of the ratio of the concentrations of the components, which, accordingly, affects the activation energy of the compounds.

Thermodynamic characteristics of soft wheat flour $(n=3, p \leq 0.05)$

Table 3

\begin{tabular}{|c|l|c|c|c|c|}
\hline № & \multicolumn{1}{|c|}{ Indicator } & $\begin{array}{c}\text { Sample } \\
\mathbf{1}\end{array}$ & $\begin{array}{c}\text { Sample } \\
\mathbf{2}\end{array}$ & $\begin{array}{c}\text { Sample } \\
\mathbf{3}\end{array}$ & $\begin{array}{c}\text { Sample } \\
\mathbf{4}\end{array}$ \\
\hline 1 & Enthalpy, J/g & 40,06 & 37,70 & 35,63 & 36,28 \\
\hline 2 & Specific moisture content, g/kg & 8,33 & 7,36 & 6,51 & 6,74 \\
\hline 3 & $\begin{array}{l}\text { Ratio of the concentrations of the } \\
\text { components of the mixture, g/kg }\end{array}$ & 8,40 & 7,41 & 6,55 & 6,78 \\
\hline 4 & $\begin{array}{l}\text { Vapor concentration at saturation, } \\
\text { g/m } \text { m }^{3}\end{array}$ & 15,97 & 16,12 & 16,21 & 16,28 \\
\hline 5 & Partial water vapor pressure, hPa & 13,33 & 11,77 & 10,42 & 10,78 \\
\hline 6 & Saturated vapor pressure, hPA & 21,52 & 21,70 & 21,86 & 21,96 \\
\hline 7 & Water activity (aw) & 0,619 & 0,542 & 0,477 & 0,491 \\
\hline
\end{tabular}

The highest enthalpy is for sample 1, which has a base ratio of amylose and amylopectin. Any change in the structure of starch granules leads to a decrease in enthalpy. In particular, softening the structure and weakening the bonds of the starch-protein matrix (sample 2) reduces the enthalpy by $2.3 \mathrm{~J} / \mathrm{h}$. The lowest value of enthalpy is sample 3 , which contains only amylopectin in the starch granules. At the same time, the influence of other components of flour should be noted. Thus, the increased composition of micro- and macroelements (sample 4) leads to a decrease in enthalpy by $3.7 \mathrm{~J} / \mathrm{g}$ accordingly, aw has a similar nature of reduction. This indicates the dependence of this indicator on the energy of the reactions in the flour and on the influence of other components such as: the structure of the starch granule, the influence of micro- and macronutrients. 


\section{Determination of aw for samples of modified wheat flour}

As studies have shown (Table 4), the physical modification of wheat flour leads to a decrease in aw in the samples.

Thermodynamic characteristics of modified wheat flour $(n=3, p \leq 0.05)$

Table 4

\begin{tabular}{|c|l|c|c|c|c|c|}
\hline № & \multicolumn{1}{|c|}{ Indicator } & Control & $\begin{array}{c}\text { Sample } \\
\mathbf{1 M}\end{array}$ & $\begin{array}{c}\text { Sample } \\
\mathbf{2 M}\end{array}$ & $\begin{array}{c}\text { Sample } \\
\mathbf{3 M}\end{array}$ & $\begin{array}{c}\text { Sample } \\
\mathbf{4 M}\end{array}$ \\
\hline 1 & Enthalpy, J/g & 43,89 & 45,26 & 44,57 & 45,20 & 45,12 \\
\hline 2 & $\begin{array}{l}\text { Specific moisture content, } \\
\text { g/kg }\end{array}$ & 8,72 & 9,33 & 9,04 & 9,28 & 9,34 \\
\hline 3 & $\begin{array}{l}\text { Ratio of the } \\
\text { concentrations of the } \\
\text { components of the } \\
\text { mixture, g/kg }\end{array}$ & 8,80 & 9,42 & 9,12 & 9,37 & 9,43 \\
\hline 4 & $\begin{array}{l}\text { Vapor concentration at } \\
\text { saturation, g/m }\end{array}$ & 18,78 & 18,57 & 18,64 & 18,64 & 18,40 \\
\hline 5 & $\begin{array}{l}\text { Partial water vapor } \\
\text { pressure, hPa }\end{array}$ & 13,95 & 14,91 & 14,45 & 14,83 & 14,92 \\
\hline 6 & $\begin{array}{l}\text { Saturated vapor pressure, } \\
\text { hPA }\end{array}$ & 25,54 & 25,24 & 25,34 & 25,34 & 24,99 \\
\hline 7 & Water activity (aw) & 0,546 & 0,591 & 0,570 & 0,585 & 0,597 \\
\hline
\end{tabular}

In particular, for sample 1 is reduced from 0.619 to 0.591 . At the same time, the change in the structure of the starch granule leads to an increase in the water activity index for flour samples: sample 2 from 0.477 to 0.585 , sample 3 from 0.542 to 0.570 , sample 4 from 0.491 to 0.597 . It should be noted that the value of aw is 0.546 , which indicates an in-depth thermal modification due to extrusion. Thus, the structure of the starch granule affects the value of water activity.

The water activity of the product determines its ability to evaporate from the product relative to the ability to evaporate pure water at the same temperature (Tsukanov MF and Chernomorets AB, 2010). Accordingly, the change in the aw between the native flour and the modified is influenced by the structure of the starch-protein matrix, in which due to ionic bonds, hydrophobic and hydrogen bonds and Van der Waals forces, the interaction of product moisture with compounds such as starch and protein (Miyazaki MR et.al., 2006).

The value of the water activity index for samples of modified wheat flour is in the range above 0.5, which indicates low fragility (Hazelton JL et. Al., 2003) and the effect of fat (Červenka L. et al., 2006) on this indicator, which practically does not bind water (Rodel W. et. al., 2001). At the same time, the change in the values of water activity indicators for native flour samples and their modifications indicates the influence of the quantitative content of protein and sugars and their qualitative composition (Tanaka M. et. Al., 2011).

The value of ethalpy for all samples of modified flour increases, on J/g: sample 1 - 5.2; sample 2-6.87 sample 3-9.57; sample 4-5.84. Therefore, the energy increases to change the structure of the compounds under the action of temperature. 
In addition to influencing chemical reactions and the development of microorganisms, water activity affects the texture of products (Schmidt S.J. et. al., 2004). At the maximum value of the water activity index allowed in dry products and without loss of the specified properties, the indicator varies in the range of $0.35-0.5$, and for softened products, which should not have brittle properties, the indicator should exceed 0.5 (Chervenka L. et al., 2006).

\section{Correlation coefficients of $a_{w}$ for wheat flour}

According to the obtained results (Tables 3 and 4), correlation coefficients were obtained (Table 5).

Table 5

Statistical parameters of the regression dependence of the water activity index on the component composition of wheat flour $(n=3, p \leq 0.05)$

\begin{tabular}{|l|c|c|c|c|}
\hline \multirow{2}{*}{ Indicator } & \multicolumn{3}{|c|}{ Correlation coefficients } & $\begin{array}{c}\text { Determination } \\
\text { coefficient } \mathrm{R}^{2}\end{array}$ \\
\cline { 2 - 5 } & $\mathrm{A}^{*}$ & $\mathrm{~B}^{* *}$ & $\mathrm{C}^{* * *}$ & \\
\hline Native & 0,0227 & 0,1586 & 0,7583 & 0,9819 \\
\hline Modified & 0,0083 & 0,0380 & 0,6188 & 0,8112 \\
\hline $\mathrm{p}<0,001^{*}, \mathrm{p}<0,01^{* *}, \mathrm{p}<0,05^{* * *}$.
\end{tabular}

With a constant value of aw and an increase in the processing temperature of the flour, the amount of adsorbed water increases. Samples of flour differ in the composition of carbohydrates $(p<0.001)$, proteins $(p<0.01)$, fats $(p<0.05)$. Therefore, with temperature modification there are structural changes of the main components with the formation of simpler ones.

\section{Influence of aw of modified flour samples on suitability for storage}

The influence of the use of sample $1 \mathrm{M}$ in the recipe of bread by intensive technology on the shelf life of the loaf was studying. The main problem of accelerated technology is the rapid hardening of loaves, which begins to be observed after cooling. This is manifeste in increased tidiness, reduced elasticity of the crumb and the ability to restore shape after pressing. Traditionally, the method of extending the shelf life of products, based on which the reduction of moisture content is achieve by concentration or dehydration (Sereno A. M. et al., 2001). The range of moisture-binding additives is constantly expanding, offering compounds or ingredients such as (Rodel W. et al., 2011): salts, polysaccharides, amino acids, proteins, polyhydric alcohols and more. It is known (Tsukanov M.F. and Chernomorets A.B., 2010), substances such as sugar and salt reduce the $a_{w}$ in the product. In particular, in a saturated solution of sugar at $20^{\circ} \mathrm{C}$, the activity of water is 0.864 , and table salt -0.753 (Červenka L. et al., 2006). The influence of the method of processing raw materials and semifinished products on the value of the moisture activity index, is known (Sereno A. M. et al., 2001). In this direction, the modification of flour plays a role as a moisture-retaining component in the food product.

At a value of $\mathrm{a}_{\mathrm{w}}=0.6-0.8$, which corresponds to a moisture content of the product up to $40 \%$ (Hazelton JL et al., 2003) for a long time there are no processes associated with the 
deterioration of product quality (Scott WJ et. Al., 1957 ). Such $\mathrm{a}_{\mathrm{w}}(0,619)$ has a sample 1, that usually flour with such a component composition is used for the manufacture of bakery products. Obviously, the presence and amount of hydrophilic substances such as starch and sugars, which modify the flour interact with water in the flour particles and thus form new ionic and hydrogen bonds, which reduces the amount of available moisture in the product (Hazelton JL et al., 2003).

The effect of the use of modified flour in the recipe of bread by intensive technology on the shelf life of the loaf was studied. The main problem of accelerated technologies is the rapid hardening of loaves, which begins to be observed after cooling. This is manifested in increased lidiness, reduced elasticity of the crumb and the ability to restore shape after pressing.

Received bread according to usual recipe and bread in which $10 \%$ of flour was replaced by modified flour. The taste of the products is different: when used in this technology, sourdough is allowed in the products, which is noticeable in the control samples. However, with increasing replacement of wheat flour, the sour taste is almost not felt. The taste is typical of wheat bread, in products with the replacement of wheat flour is wetter and more pleasant to the taste. In products with wheat flour replacement, the state of the crumb differs (Figure 1) by a denser thick-walled porosity.

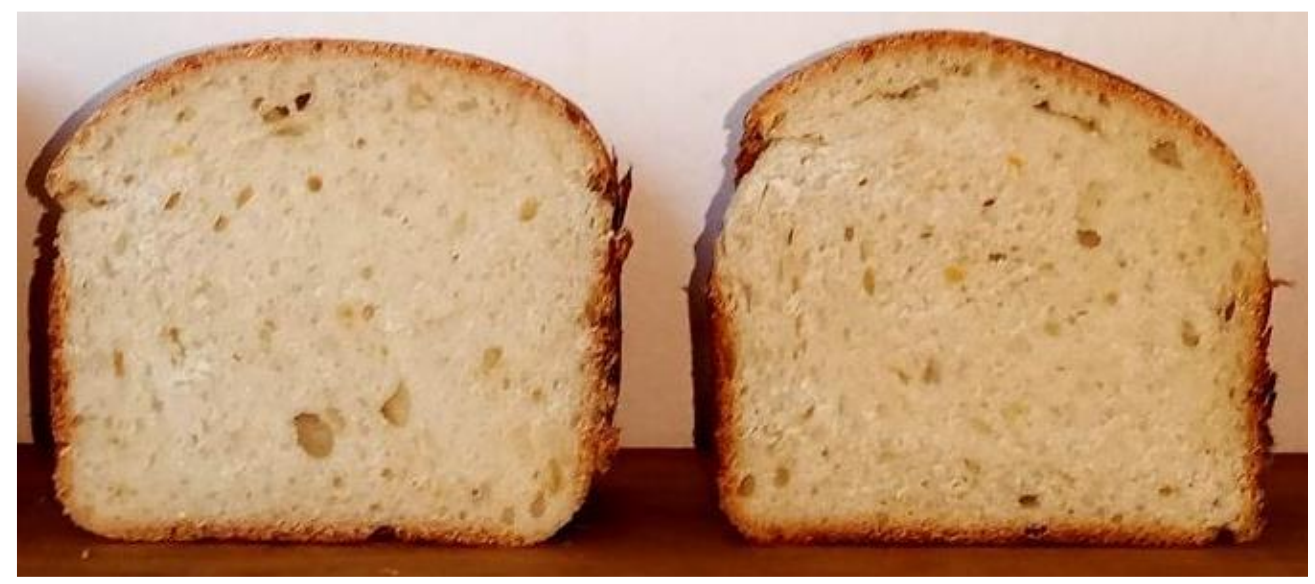

a

b

\section{Figure 1. Bread crumb: \\ a-according to the usual recipe; \\ b - with the replacement of $10 \%$ wheat flour with modified wheat flour.}

This is increased by $1 \%$ humidity of the product compared to the control sample. However, in the case of replacing $30 \%$ of extruded flour, the crumb has a slight stickiness.

According to physicochemical parameters (Table 6), it is noted that the products have an underestimated volume, which is due to the complete exclusion of compressed yeast from the recipe. 
Quality indicators of the obtained loaves

Table 6

\begin{tabular}{|l|c|c|}
\hline \multicolumn{1}{|c|}{ Quality indicators } & Control & Replacement 10\% \\
\hline Weight of the dough, g & 250 & 250 \\
\hline Weight of hot bread, g & 232 & 224 \\
\hline Weight of cold bread, g & 224 & 215 \\
\hline Volume, $\mathrm{cm}^{3}$ & 750 & 660 \\
\hline Specific volume, $\mathrm{cm}^{3} / \mathrm{g}$ & 3,35 & 3,29 \\
\hline Humidity, \% & 40 & 41 \\
\hline Acidity, deg & 1,2 & 68 \\
\hline Porosity, \% & 69 & 10,2 \\
\hline Baking, \% & 7,2 & 4,3 \\
\hline Drying, \% & 3,4 & \\
\hline
\end{tabular}

The moisture content of the products increases with the replacement of wheat flour, which is due to the greater water absorption capacity of the modified flour. The brightly colored crust of the products indicates a sufficient accumulation of sugars involved in the reaction of melanoid formation.

Change of deformation of loaves at introduction in a compounding of $10 \%$ of flour of the modified (table 7)

Table 7

Evaluation of changes in the quality of bread during storage

\begin{tabular}{|c|c|c|c|}
\hline \multirow{2}{*}{$\begin{array}{l}\text { Structural and mechanical } \\
\text { properties of crumb }\end{array}$} & \multirow[t]{2}{*}{ Control } & \multicolumn{2}{|c|}{ replacement $10 \%$ flour } \\
\hline & & modified & extruded \\
\hline \multicolumn{4}{|c|}{ General deformation $\mathrm{H}$ gen, units ave } \\
\hline in 4 hours & 61 & 78 & 48 \\
\hline in 48 hours & 33 & 48 & 32 \\
\hline \multicolumn{4}{|l|}{ Plastic deformation of $\mathrm{H} \mathrm{pl}$, units ave. } \\
\hline in 4 hours & 51 & 58 & 28 \\
\hline in 48 hours & 27 & 40 & 21 \\
\hline \multicolumn{4}{|c|}{ Elastic deformation of $\mathrm{H}$ el.d., units ave. } \\
\hline in 4 hours & 10 & 23 & 12 \\
\hline in 48 hours & 6 & 9 & 9 \\
\hline \multicolumn{4}{|l|}{ Covering, \% } \\
\hline in 4 hours & 4,9 & 1,7 & 0,1 \\
\hline in 48 hours & 6,5 & 2,1 & 0,5 \\
\hline \multicolumn{4}{|l|}{ Wetting,\% to DM } \\
\hline in 4 hours & 271 & 276 & 164 \\
\hline in 48 hours & 227 & 221 & 148 \\
\hline
\end{tabular}


The main problem of accelerated technologies is the rapid hardening of finished products (Pico J., et. al., 2015), which begins to be observed immediately after cooling. This is manifested in increased crunchiness, reduced elasticity of the crumb. Therefore, one of the main tasks in the improvement of accelerated technologies is on the one hand to improve the taste and aroma of finished products, and on the other - to improve quality during storage.

It was found that for samples of loaves obtained with the replacement of $10 \%$ by modified flour, there are signs of better safety and stability of quality during storage for 48 hours. In the samples with the replacement of flour with extruded flour there was a decrease in the total deformation of the crumb after cooling from 48 to 32 units, with the replacement of the modified flour there was a decrease in the total deformation from 78 to 48 units etc. Crispiness, as one of the main signs of loss of freshness (Torrieri E., et. al., 2014), was the highest in the control, and in samples of loaves with the replacement of modified flour, this figure was lower by $65-80 \%$. Slowing down of hardening of samples made with extruded or modified flour is confirmed by wetting indicators.

\section{Effect of adding $10 \%$ of modified flour to the bread recipe for storage of loaves}

The obtained samples of bread loaves obtained using sourdough on wheat flour and replacement of wheat flour with modified flour were evaluated. One of the problems with the quality of bread is the frequent cases of microbiological spoilage - mold and potato disease (especially in summer). To determine the effect of yeast on wine yeast and different types of flour on the microbiological stability of the finished products, studies were performed at a temperature of $35-40{ }^{\circ} \mathrm{C}$ in provocative conditions to observe the appearance of signs of potato disease and mold.

The mold was observed on day 8 in the bread sample with the replacement of $10 \%$ of wheat flour with iodized, in the control sample - on the 9th day of storage. According to the signs of potato disease, it was found in loaves: control sample on the 7th day of storage, with modified flour - on the 9th day of storage. The development of micromycetes was observed in loaf samples made using sourdough on a loaf sample with modified flour on the 12th day of storage and with extruded flour on the 10th day.

The use of ingredients with low aw shows an inhibitory ability to develop potato disease and micromycetes, which prolongs the storage of bread loaves for 1-2 days. The change in the component composition of the flour after its modification significantly affected its technological quality. The use of such a product in the production of food products helps to extend their shelf life, and, accordingly, for a long time to promote the preservation of organoleptic properties and to show stability to the action of microorganisms.

\section{Conclusions}

1. The indicator of water activity for wheat flour and its modifications is determined, which is in the range of $0.491-0.619$ for native wheat flour and in the range of 0.570 0.597 for modified wheat flour. According to the general classification, modified flour belongs to products with low humidity.

2. The indicator of water activity is influence not only by the content of such compounds as protein, fat, sugar, but also the structure of the starch polymer. Using samples of wheat flour with different structure of starch polymer, there is also a pattern of reducing the water index after modification of the flour. 
3. Modified wheat flour for the value of water activity can be used as a moistureretaining component of flour products, which will increase the shelf life of loaves produced on sourdough by accelerated technology.

4. Correlation coefficients are calculated and a significant impact of the modification process on the quality of the finished product is showing - flour samples have become more stable and suitable for a longer period to maintain organoleptic characteristics.

\section{References}

Abbas K.A., Sahar K. K., Anis S.M.H. (2010), Modified Starches and Their Usages in Selected, Food Products: A Review Study Journal of Agricultural Science, 2(2), pp. 90-100.

Birch A.N., Petersen M.A., Hansen A.S. (2013), Aroma of wheat bread crumb, J. Cereal Chem., 91, pp. 105-114.

Červenka L., Brozkova I., Vytrasova J. (2006), Effects of the principal ingredients of biscuits upon water activity, Journal of Food and Nutrition Research, 45(1), pp. 39-43.

Hazelton J.L., Desrochers J.L., Walker, C.E. (2003), Chemistry of biscuit making. Encyclopedia of food science and nutri tion, Academic Press, Amsterdam, New York, pp. 533-539.

Kataoka Y., Kitadai N., Hisatomi O., Nakashima, S. (2011), Nature of hydrogen bonding of water molecules in aqueous solutions of glycerol by Attenuated Total Reflection (ATR) infrared spectroscopy, Appl. Specectrosc., 65, pp. 436-441, DOI: 10.1366/10-06183.

Khomichak L..M, Shtangeeva N.I., Kuznietsova I.V., Vysotska S.I. (2019), Study of the method of preparation of flour for modification, Food resources, 12, pp. 161-167.

Kuznietsova I.V., Khomichak L.M., Dzhogan O.I., Zaychuk L.P., Tkachenko S.V., Vysotska S.I. (2020), Study of starch change during the process of wheat flour modification, Food resources, 14, pp. 110-117.

Leistner L., Gorris, (1995), Food preservation by hurdle technology, Trends Food Sci. Technol., 6, pp. 41-46, DOI: 10.1016/S0924-2244(00)88941-4.

Pico J., Bernal J., Gómez M. (2015), Wheat bread aroma compounds in crumb and crust: a review, Food Res. Int., 75, pp. 200-215.

Rodel W., Kress-Rogers E., Brimelow C.J.B. (2001), Water activity and its measurement in food, In: Instrumentationand Sensors for the Food Industry, 2nd edition Woodhead, Cambridge, pp. 453-483.

Rybalka O.I. (2008), Alien genetic variability in improving wheat grain quality, Cytology and genetics, 42(4), pp. 18-26.

Rybalka O.I., Axelrud D.V. (2004), What are the characteristics of biscuit flour? Influence of hardness and biochemical composition of flour on the quality of biscuits, Collection of scientific works of SGI-NAC NAIS, 6(46), pp. 247-253

Rybalka O.I., Chervonis M.V., Toporash I.G. (2005), Wheat waxy with unique properties os starch: possible directions of its use, Grain storage and processing, 7, pp. 2428.

Schmidt S.J. (2004), Water and solids mobility in foods, Advances in Food and Nutritional Research, 48, pp. 1-101.

Scott W.J., Mrak E.M., Stewart G.F. (1957), W ater relations of food spoilage microorganisms, In: Advances in Food Research, VII, Academic Press, New York, pp. 83127. 
Sereno A.M., Hubinger M.D., Comesana, J.F., Correa, A. (2001), Prediction of water activity of osmotic solutions, Journal of Food Engineering, 49, pp. 103-114.

Tanaka M., Sato K., Kitakami E., Kobayashi S., Hoshiba T., Fukushima K. (2015), Design of biocompatible and biodegradable polymers based on intermediate water concept, Polym. J., 47, pp. 114-121, DOI: 10.1038/pj.2014.129.

Torrieri E., Pepe O., Ventorino V., Masi P., Cavella S. (2014), Effect of sourdough at different concentrations on quality and shelf life of bread, Food Sci. Technol., 56, pp. 508516.

Tsukanov M.F., Chernomorets A.B. (2010), Technological aspects of the indicator "water activity" and its role in ensuring the quality of catering products, Technical and technological problems of the service, 1(11), pp. 58-63.

Venturi C., Sanmartin I., Nari A., Andrich G., Zinnai A. (2016), Effect of the baking process on artisanal sourdough bread-making: A technological and sensory evaluation, Agrochimica, 60(3), pp. 222-234. 